\title{
Production Technology of Synthetic Iron to Ensure the Efficiency of Casting Production
}

\author{
Kukartsev Viktor Alekseevich ${ }^{1,}$, Kukartsev Vladislav Viktorovich ${ }^{1,2, b}$ and \\ Tynchenko Vadim Sergeevich ${ }^{1,2, c^{*}}$
}

\author{
${ }^{1}$ Siberian Federal University, 79, Svobodny pr., Krasnoyarsk, 660041, Russia \\ ${ }^{2}$ Reshetnev Siberian State University of Science and Technology, 31, Krasnoyarsky Rabochy Av., \\ 660037 Krasnoyarsk, Russia
}

asarabernar777@mail.ru, bvlad_saa_2000@mail.ru, 'vadimond@mail.ru

Keywords: casting production, synthetic iron, casting alloys, foundry.

\begin{abstract}
Modernization of physical and mechanical properties of casting alloys, through the introduction of new processes, which can be used to obtain a precise casting with a smooth surface, which does not require machining, with a constant increase in the productivity of the implemented processes changing the technological and economic profile of modern foundry. The most advanced equipment is the induction crucible, melting furnace, which belongs to the main production assets and has a direct impact on productivity and, consequently, on profitability. For this reason, it is the main factor determining the content of the development strategies of the enterprise as a whole. Since 2000, iron scrap has been gone, due to the active sale of it abroad, the cost of pig iron and foundry has increased dramatically, in addition, increased the cost of their delivery. This led to higher prices in the production of castings made of synthetic iron, due to the increase in the cost of batch materials. In addition, there were problems with the use of acidic lining, as the cheapest and has a high resistance as a part of the metal began to use an increased amount of scrap steel and for this reason to raise the melting temperature above 1450 Celsius. For this reason, the efficiency of production has to pay great attention.
\end{abstract}

\section{Introduction}

A special place in the industry is foundry, related to the procurement phase of mechanical engineering. Production of castings is one of the most widely used technological processes of formation of details owing to cheapness and possibility of its all-round application. This process can be used in the manufacture of both small and large parts, both with simple and complex outlines, both for individual and for mass production [1]. Different alloys can be used for castings. In many cases, the cost of castings is less than the cost of similar parts obtained by other processes [2].

The specifics of the foundry industry allow us to talk about well-established approaches to the choice of marketing strategies and their further implementation. The fundamental category in strategic marketing is the concept of the enterprise mission. It is accepted that the mission of the foundry (workshop) can be defined as «providing the consumer with blanks of General machinebuilding (special) purpose, as close as possible to the profile (size) of the future part in full compliance with the requirements for mechanical, physical, technical and special properties specified in the technical conditions of the customer».

Continuous improvement of physical and mechanical properties of casting alloys, improvement of old and introduction of new processes that allow to obtain precise casting with a smooth surface that does not require machining, and, finally, a constant increase in the productivity of the processes used change not only the technological but also the economic profile of modern foundry [3, 4]. To date, the structure of the casting alloys used is shown in Figure 1.

Based on it, it follows that cast iron is the most common casting alloy. The share of cast parts on average accounts for $50-70 \%$ of the mass (in the machine tool industry up to $90 \%$ ) and $20-22 \%$ of the cost of machines. The most consumed iron is gray iron, which is used for smelting various melting furnaces. 

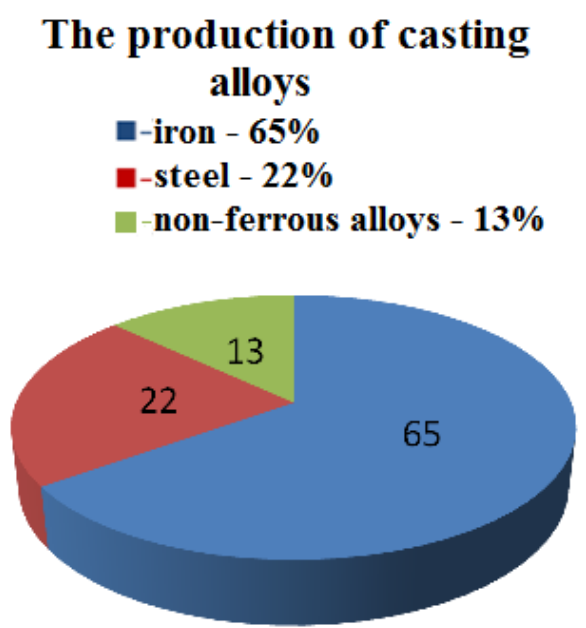

Fig. 1. Structure of investment cast alloys.

The most advanced is the induction melting furnace used in the foundry, which belongs to the main production assets of the enterprise and has a direct impact on productivity and, consequently, on profitability [5]. For this reason, it is the main factor determining the content of the development strategies of the enterprise as a whole. Increasing the reliability of its work is one of the main tasks of reproduction of fixed assets [6]. Induction melting furnace has a high performance in the smelting of alloys, high lining resistance, energy efficiency and optimization of maintenance costs [7]. Its use allows for more detailed thermal treatment, refining, modification and alloying of liquid metal [8]. The advantage of induction furnaces is increased technological flexibility: it is possible to obtain cast iron of any chemical composition, produce liquid metal in arbitrary portions, store metal for a long time without changing its properties, use batch materials of low volume mass and mechanize the melting processes $[9,10]$.

The first block of workshops with induction furnaces of industrial frequency (IFF) instead of trolleys, in our country, began to work in 1963 at the Kaunas iron foundry. Institute «Lengiprotyazhmash» for several years in projects of foundries included the induction furnace of industrial frequency. The main purpose of induction furnaces is the smelting of synthetic iron [11]. The initial raw materials for the production of synthetic iron are steel scrap, sheet metal, chips and other low-cost metal waste. They provide effective use of metal waste of small volume weight. The advantage of this technology is the ability to realize the remelting of waste at the site of their formation [12]. The use of cheap metal waste, reduces the cost of synthetic iron by $25-39 \%$ compared to secondary remelting iron [13].

Since the maintenance staff is limited from the effects of heat, dust, noise, gases from the combustion of fuel, therefore improved sanitary and hygienic working conditions. When operating induction furnaces air basin clogged many times less than in the cupola process, which requires bulky, costly cleanup tool, which gives a great advantage, if the company is in the city. The specific consumption of refractory materials is reduced - for an induction furnace it is $3 \mathrm{~kg} / \mathrm{t}$, an arc furnace with acid lining - 17.6 and for a cupola $-27 \mathrm{~kg} / \mathrm{t} \mathrm{[14].}$

\section{Problem statement}

In the traditional metal smelting of synthetic iron in induction crucible furnaces of industrial frequency (Figure 2), the share of steel scrap is $25-30 \%$, it corresponds to the conduct of melting at $\mathrm{t} \leq 1450{ }^{\circ} \mathrm{C}$. Years of operation have proven the advantages of these furnaces: the reliability of the design; ease of maintenance and repair; the possibility (if necessary) of conducting the smelting process by one smelter when installing two furnaces with a combined service site; equalization of the temperature and chemical composition of the melt, its active interaction with the slag due to circulation. 


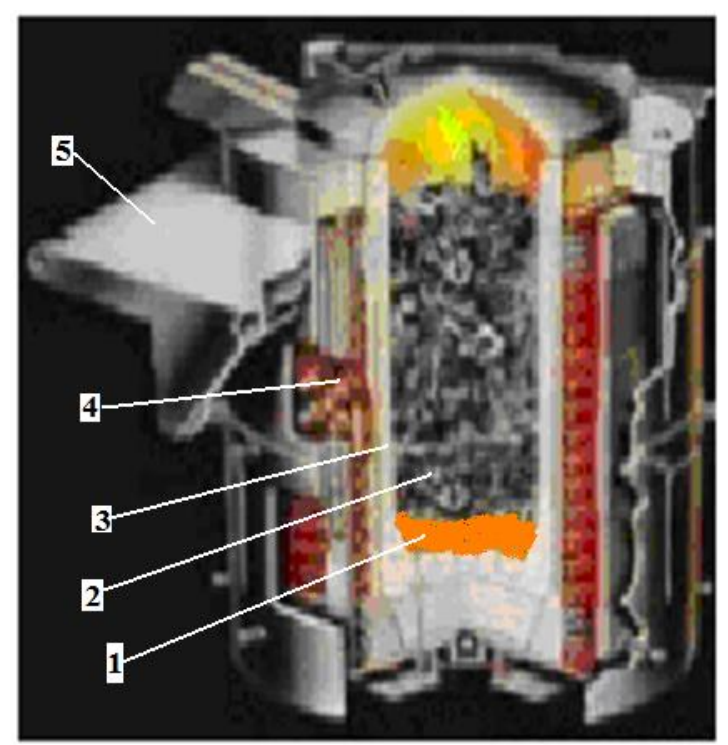

Fig. 2. Induction crucible furnace:

1- sump (liquid residue), 2 - metal, 3 - lining, 4 - inductor, 5 - furnace body.

Since 2000, iron scrap has been gone, due to the active sale of it abroad, the cost of pig iron and foundry has increased dramatically, in addition, increased the cost of their delivery. This led to higher prices in the production of cast iron castings due to the increase in the cost of charge materials. In addition, there were problems with the use of acidic lining, as the cheapest and has a high resistance as a part of the steel mills began to use an increased amount of scrap steel and for this reason to raise the melting temperature above $1450{ }^{\circ} \mathrm{C}$.

Practice has shown that the use of the melting temperature of synthetic iron $1500-1550{ }^{\circ} \mathrm{C}$ leads to a decrease in the resistance of the lining from 300-350 heats to 180-200 heats. This reduces the production efficiency due to the forced downtime associated with the furnace relining and increasing the cost of materials and electricity $[15,16]$. So, the duration of the process of refouting (from the beginning of stopping the furnace to the first full drain of the finished melt) of the IFF-1 furnace is from 2.5 to 3 days. In the conditions of modern economy, to increase the competitiveness of finished products, it is required to obtain both inexpensive and high-quality blanks, with a low level of marriage [17].

The cost of castings is influenced by both the chosen melting unit and the materials used for its lining. Acidic lining based on quartzite, has high resistance, if it (after sintering) formed three zones - sintered, semi-baked and loose (Figure 3), but at temperatures above $1450{ }^{\circ} \mathrm{C}$ the process of transition from one zone to another is much faster, which speeds up the process of its wear [18].

To improve the properties of acidic lining, repeated attempts were made to use additives from a mixture of oxides of calcium, iron, sodium, phosphorus-containing additives, a special Frit fused from a mixture of silica and sodium oxide or silica with oxides of iron and calcium, tridimite seed in the form of a fine grinding of tridimitized silica or an additive of $30 \%$ corundum. It was proposed and the introduction of high temperature additives in the form of $\mathrm{ZrO} 2, \mathrm{Pr} 2 \mathrm{o} 3$, chromogenesis slag, chromite. However, all of them have not found industrial application.

\section{Proposed problem solution}

A reliable solution to the problem is the high-temperature technology of smelting synthetic iron at $1500-1600^{\circ} \mathrm{C}[19]$. 


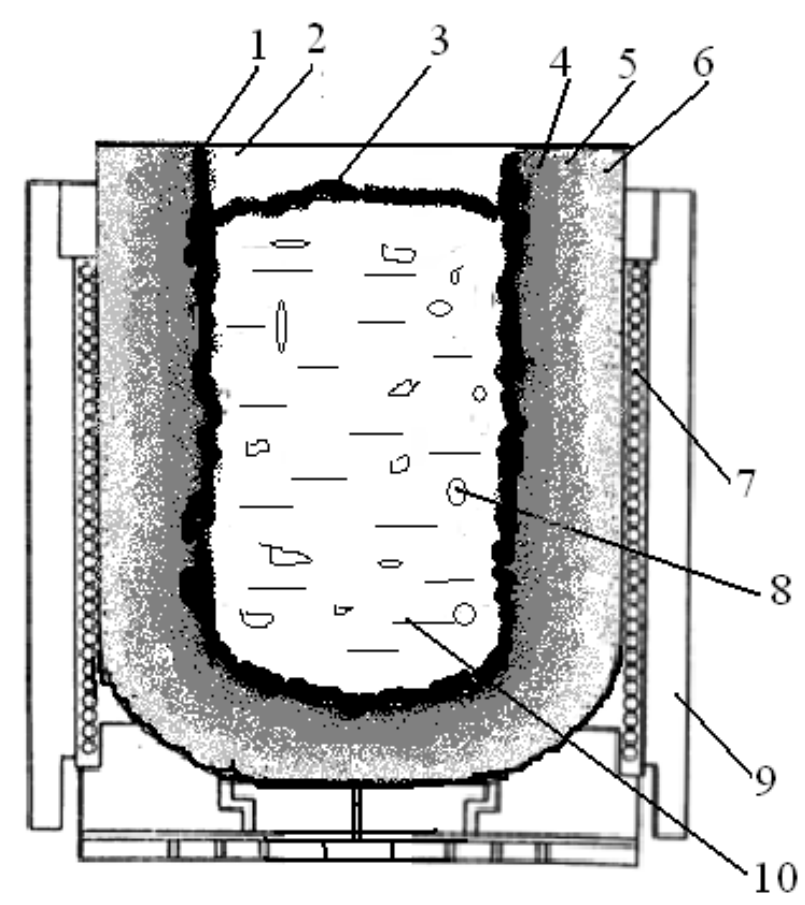

Fig. 3. Layout of the zones of quartzite lining in IFF-1 furnace:

1 - sintered crust lining that exists at a temperature of less $1200{ }^{\circ} \mathrm{C}, 2$ - gas phase of the furnace 3 to the liquid slag on the surface of the melt, 4 - sintered area lining, 5 - polyspectra area lining, 6 - zone nespereira mass (buffer), 7 - inductor furnace, 8 gas contained in the melt, 9 - the furnace housing, $10-$ melt.

It allows you to reduce the cost of materials and electricity through the use of cheap steel scrap instead of cast iron, to maintain the resistance of the lining in the amount of 300 melting, to be from high-temperature furnaces for heat treatment of the original quartzite and heat-resistant containers. This technology is based on the application of a new composition of acidic lining. Its implementation allows to increase the efficiency of synthetic iron smelting and to save costs for the purchase of charge and lining materials. The cost savings calculation is presented for the melting furnace IFF-1 in Table 1.

Table 1. Cost savings calculation for the melting furnace IFF-1

\begin{tabular}{|l|l|l|l|}
\hline \multirow{2}{*}{ Material } & \multirow{2}{*}{$\begin{array}{c}\text { Market value, } \\
\text { RUB/kg }\end{array}$} & \multicolumn{2}{c|}{$\begin{array}{c}\text { Consumption, } \\
\text { kg / RUB per 1 ton }\end{array}$} \\
\cline { 3 - 4 } & & \multicolumn{1}{c|}{ Traditional technology } & \multicolumn{1}{c|}{$\begin{array}{c}\text { High temperature } \\
\text { technology }\end{array}$} \\
\hline $\begin{array}{l}\text { The sump (the liquid } \\
\text { remainder) }\end{array}$ & $50 \%$ of casting & $300-350 / 12000-14000$ & $100 / 4000$ \\
\hline Return of production & $80 \%$ of casting & $220-280 / 14080-17920$ & - \\
\hline $\begin{array}{l}\text { Foundry (pig iron) and } \\
\text { cast iron scrap }\end{array}$ & $25-40$ & $170-200 / 4250-8000$ & - \\
\hline $\begin{array}{l}\text { Ferromanganese, } \\
\text { ferrosilicon }\end{array}$ & $48-54$ & $5-10 / 250-500$ & $10-15 / 500-750$ \\
\hline Steel scrap & $9-12$ & $300-350 / 3000-3500$ & $885-890 / 8850-8900$ \\
\hline Carburizer & $2-3$ & $5-6 / 12,5-15$ & $10-20 / 25-50$ \\
\hline Quartzite & $7-9$ & $2,83 / 22,64$ & $1,9 / 15,2$ \\
\hline Electrocorundum & $32-35$ & - & $0,08 / 2,72$ \\
\hline Total input & $34335,14-43957,64$ RUB & $13392,92-13717,93$ RUB \\
\hline
\end{tabular}


In addition, the use of new technology allows the use of low-temperature heating furnaces, thereby reducing production costs, especially with regard to electricity consumption and the replacement of stainless steel with carbon used for the manufacture of containers in which the drying of quartzite is carried out.

\section{Conclusions}

To date, the bulk of the foundry is a small foundry with a production capacity from 2 to 5 thousand tons of fit castings per year. They are equipped with at least two different melting furnaces, which allow you to quickly respond to the needs of the market in castings of various alloys. Two furnaces of icht- 1 allow to make not less than 5000 tons of castings from gray cast iron. The use of high-temperature technology of synthetic iron smelting allows to increase the capacity by $60 \%$ by increasing the efficiency of the melting equipment. In addition, this technology makes it possible to produce steel castings [20], which increases the range of products and makes it possible to compensate (if necessary) the volume of orders for cast iron castings. The resulting reduction in the cost of materials used in the metal, reduces the cost of production.

\section{References}

[1] V.D. Shnajder, D. Pfennig, Modern smelting installations, Litejnoe Proizvodstvo, 5 (1993) 3537.

[2] Jan de Groot, F. Dosbach, Reliable and economical melting in medium-frequency crucible furnace, Metal and casting of Ukraine, 95 (2008).

[3] I. Riposan, M. Chisamera, S. Stan, Enhanced Quality in Electric Melt Grey Cast Irons, ISIJ International, 53 (2013) 1683-1695.

[4] M.Q. Hong, Technical improvement on structure of medium-frequency coreless induction furnace body used in melting aluminum alloy, Zhuzao/Foundry, 61 (2012) 786-789

[5] Yu. O. Curguchev, V.G. Ladozhskij, S.S. Politkovskij, Improvement of crucible induction furnace control, Liteinoe Proizvodstvo, 10 (1991) 4.

[6] V. V. Kukartsev, O. A. Antamoshkin, The combined decision-making method for the reproduction of basic production assets, Problems of mechanical engineering and automation, 2 (2011) 56-60.

[7] V. S. Sasa. Lining of induction flowing furnaces and mixers, Energoatomizdat, Moscow, 1983.

[8] V.I Laguzin., A.U. Petrov., L.I. Fireman, Induction furnaces of middle frequency of new generation, Metallurgy of machine building, 1 (2002) 4-13.

[9] B. P. Platonov, A. D. Akimenko, S. M. Bogutskaya, E. M. Kitayev, Yu. B. Platonov, A. A. Skvortsov. Induction furnaces for cast iron melting, Mashinostroyeniye, Moscow, 1976.

[10] E. Dech, Medium-frequency induction furnaces, Litejnoe Proizvodstvo, 6 (1993) 30-33.

[11] T.A Alexeeva, Induction melting with full discharge of metal, Construction and road machines, 7 (2006) 24-28.

[12] I. Yilmaz, M. Ermis, I. Cadirci, Medium-frequency induction melting furnace as a load on the power system, IEEE Transactions on Industry Applications, 48 (2012) 1203-1214.

[13] P. Futas, A. Pribulova, J. Petrik, M. Pokusova, A. Junakova, The study of synthetic cast iron quality made from steel scrap, International Multidisciplinary Scientific GeoConference Surveying Geology and Mining Ecology Management (SGEM), 18 (2018) 321-329. 
[14] O. Yu. Levkina, Model of effective management of foundry production of an aircraft building enterprise, Proceedings of the Samara Scientific Center of the Russian Academy of Sciences, 14 (2012) 126-139.

[15] A. K. Dey, Energy efficiency model for induction furnace, Proceedings Paper, 302 (2018) 7883.

[16] S. S. Chandra, An optimum design of the lining of a medium frequency induction melting furnace, International Transactions in Operational Research, 5-4 (1998) 255-259.

[17] V. A. Kukartsev, V. V. Kukartsev, A. V. Kukartsev, Effect of the temperature treatment of quartzite on the lining resistance of commercial-frequency induction crucible furnaces // Refractories and Industrial Ceramics, 3 (2018) 162-176.

[18] V. A. Kukartsev, A. I. Trunova, A. V. Kukartsev, Thermal analysis of quartzite used to line a crucible-equipped industrial-frequency induction furnace, Refractories and Industrial Ceramics, 553 (2014) 220-222.

[19] V. A. Kukartsev, A. M. Sazonov, V. G. Babkin, Effect of the addition of electrocorundum on structural-phase transformations in the quartz lining of an industrial-frequency crucible-type induction furnace, Refractories and Industrial Ceramics, 56-2 (2015) 151-154.

[20] M. Chaabet, E. Dotsch, Steelmaking based on inductive melting heat processing, VulkanVerlag Seiten, 10 (2012) 49-58. 